\title{
Motivação da Equipa: A Visão da Nossa Unidade
}

\author{
Marina Carneiro*, Mariana Marinho Moreira*
}

\section{Pontos-chave:}

A motivação é geralmente definida como o comportamento que visa um objectivo.

Na motivação para o desempenho a maioria revela desenvolver estratégias para atingir os seus objectivos e considera que tarefas diversificadas são importantes para o bom desempenho das funções, quebrando assim a monotonia. As influências no trabalho são multifatoriais, não se podendo minimizar os efeitos do fator humano a nível institucional e organizacional, sendo que a motivação representa uma variável determinante e que permite uma melhor caracterização profissional.

\section{Resumo}

A motivação é geralmente definida como o comportamento que visa um objetivo e frequentemente associada à expectativa. Os processos que envolvem as atividades diárias das organizações requerem um comportamento participativo e motivado por parte dos trabalhadores. Este conceito exerce enorme importância na gestão estratégica e de resultados da organização no sentido da conceptualização do trabalho como fonte de realização pessoal. Foi efectuado um estudo descritivo da motivação para o trabalho da equipa da USF (especialistas, internos, enfermeiros e secretários clínicos), através da aplicação de um inquérito de autopreenchimento com duas partes: caracterização sociodemográfica dos indivíduos e aplicação da Escala Multifatorial de Motivação no Trabalho (MultiMoti) - 28 itens divididos nas quatro dimensões da motivação (organização, desempenho, realização e poder, envolvimento). Os dados foram registados e tratados estatisticamente no programa Microsoft Excel $₫$ 2010. 0 inquérito foi aplicado a 21 pessoas (81\% mulheres; 19\% homens), com idades entre os 26 e os 59 anos. Responderam ao inquérito:
8 especialistas, 6 enfermeiros, 4 internos e 3 secretários clínicos; $57 \%$ fazem parte dos quadros efetivos da USF. Os principais fatores de motivação apontados foram: ambiente de trabalho (90\%), remuneração (57\%) e reconhecimento profissional (57\%). Da aplicação da Escala Multimoti: $86 \%$ referem condições de trabalho satisfatórias e $81 \%$ sentem-se realizados com as suas funções. A satisfação com a remuneração é pouco consensual. $86 \%$ consideram as tarefas diversificadas importantes para o bom desempenho das funções. 95\% desenvolvem estratégias para o alcance de metas e 95\% consideram importante a motivação transmitida quando é elogiado pelos superiores. 81\% consideram ser altamente motivados. As influências no trabalho são multifatoriais, não se podendo minimizar os efeitos do fator humano a nível organizacional; a motivação é uma variável determinante e que permite uma melhor caracterização profissional.

Palavras-chave: Motivação, organização, desempenho, equipa.

\footnotetext{
* Interna $2^{\circ}$ ano MGF | Mestrado Integrado em Medicina | USF do Mar - ACES Grande Porto IV - Póvoa de Varzim/Vila do Conde

${ }^{* *}$ Interna $4^{\circ}$ ano MGF | Mestrado Integrado em Medicina | USF do Mar - ACES Grande Porto IV - Póvoa de Varzim/Vila do Conde
} 


\section{Introdução}

A literatura sobre motivação é vasta e não reúne consenso entre autores ${ }^{1,2,3}$. Foi analisada por autores como Freud (nas décadas de 20) e Skinner (nos anos 50), tendo perdido alguma importância nos anos 70, em parte pelo desenvolvimento das teorias atribucionais e cognitivas. Contudo, nos anos 80 a motivação volta a ser um tema novamente em destaque.

A motivação é geralmente definida como o comportamento que visa um objectivo ${ }^{2}$. Surge frequentemente associada à expectativa, uma vez que para um indivíduo se motivar é necessário que tenha uma expectativa face ao resultado dessa acção.

Os processos que envolvem as atividades diárias das organizações, que buscam a eficácia, requerem um comportamento participativo e motivado por parte dos trabalhadores, pois as influências no trabalho são multifatoriais e não podemos minimizar os efeitos que o factor humano introduz nas organizações sociais. Este conceito exerce enorme importância na gestão estratégica e de resultados da organização, pois só é possível mudar o comportamento humano se houver motivação por parte do individuo para a mudança, no sentido da conceptualização do trabalho como fonte de realização pessoal.

Em termos gerais, a motivação é definida como o fenómeno que leva o indivíduo a comportar-se de uma determinada maneira ${ }^{1,2}$. O seu conceito é muito vasto e tentar medi-la não é possível no sentido quantitativo exacto. Ao longo dos anos foram desenvolvidas várias escalas.

A Escala Multifactorial de Motivação no Trabalho (Multimoti) foi desenvolvida por Ferreira, Diogo, Ferreira e Valente $(2006)^{3}$, que procuraram elaborar itens tendo em conta as características de pessoas fortemente orientadas para cada um dos tipos de motivação encontrados na literatura. A Escala Multimoti ${ }^{3}$, engloba 4 dimensões que foram propostas por vários autores:

- motivação para organização do trabalho ${ }^{4}$ (Hackman e Oldham, 1980) $)^{5}$

- motivação de realização e poder ${ }^{5}$ (McClelland, 1989)

- motivação para o desempenho ${ }^{6}$ (Locke e Latham, 1990)

- motivação comprometimento organizacional ${ }^{7}$ (Allen e Meyer, 1990)

O instrumento original é composto por 65 itens, porém a escala final é composta por 28 itens que avaliam quatro dimensões da motivação no trabalho: a motivação no trabalho tendo em vista a organização do trabalho ${ }^{1-7}$, a motivação para o desempenho ${ }^{8-14}$, a motivação para a realização e poder ${ }^{15-21}$ e a motivação para o envolvimento ${ }^{22-28}$. A escala de respostas é do tipo Likert com 5 pontos (1=discordo totalmente, $2=$ discordo, $3=$ não concordo nem discordo, $4=$ concordo, $5=$ concordo totalmente).

\section{Métodos}

O objectivo deste estudo compreendia a caracterização sociodemográfica da equipa de uma unidade de saúde familiar (USF) e avaliação da motivação para o trabalho dos diferentes elementos da equipa, segundo as suas quatro dimensões (organização, desempenho, realização e poder, envolvimento), de forma a avaliar a necessidade de implementação de medidas correctivas de forma a respeitar as diferenças individuais, necessidades e competências distintas.

Realizou-se um estudo descritivo da motivação da equipa da USF, através da aplicação de um inquérito, simultaneamente a todos os participantes, com duas partes:

\section{- Caracterização sociodemográfica dos indivíduos -} sexo, idade, nacionalidade, estado civil, número de filhos, profissão, número de anos de experiência, religião, existência de hobbies, hábitos tabágicos, etílicos, consumo de substância ilícitas, existência de doenças crónicas, medicação crónica efectuada;

- Escala Multifactorial de Motivação no Trabalho (MultiMoti) - questionário validado que abrange as quatro dimensões da motivação - cada uma das quatro dimensões da motivação foi avaliada com 7 questões, num total de 28.

Os dados recolhidos foram registados e tratados estatisticamente no programa Microsoft Excel $® 2010$.

\section{Resultados}

Segue-se a apresentação dos resultados obtidos pela aplicação da Escala Multi-Moti, segundo cada uma das suas dimensões.

\section{Motivação no trabalho tendo em vista a organização em que se trabalha}

Relativamente às condições de trabalho em que exercem as suas funções, $86 \%$ concordou existirem condições satisfatórias e $81 \%$ referiram sentir-se realizados com as funções desempenhadas. 
A opinião sobre a satisfação com a remuneração foi pouco consensual, 38\% mostraram-se insatisfeitos, 24\% manifestaram indecisão e 38\% concordaram. 0 feedback recebido no trabalho foi referido como factor motivacional em $81 \%$ dos casos. Quanto ao processo de tomada de decisões apenas $48 \%$ dos elementos da USF concordou que todos colaboram neste tipo de actividade, verificando-se uma percentagem de indecisão de $14 \%$ e de discordância de 38\%. 66\% dos inquiridos considerou trabalhar num ambiente de cooperação entre colegas e $76 \%$ considerou que a organização permite o desenvolvimento de objectivos profissionais.

\section{Motivação para o desempenho}

$62 \%$ consideraram que as avaliações periódicas são motivadoras partilhando de opinião contrária 15\% dos inquiridos. A mesma percentagem de inquiridos afirmou que gostaria de ser avaliado periodicamente, contudo apenas 57\% afirmaram gostar de ser avaliados no desempenho das tarefas. Relativamente ao campo da emotividade, podemos concluir que $71 \%$ dos profissionais da USF concordaram que no desempenho de tarefas é importante demonstrar alguma emotividade enquanto 19\% discordaram com esta situação.

Quanto ao desenvolvimento de estratégias para o alcance de metas 95\% afirmaram ter este hábito. Cerca de $86 \%$ dos inquiridos consideraram que tarefas diversificadas são importantes para o bom desempenho das funções quebrando assim a monotonia.

Quanto à existência de competitividade 67\% consideraram existir competitividade no grupo de trabalho, enquanto que $14 \%$ discordaram.

\section{Motivação por realização e poder}

Apenas $62 \%$ dos elementos da USF concordaram ter perspectivas de carreira. No entanto, o desempenho de funções com maior responsabilidade foi pouco consensual - 1/3 concordou, 1/3 discordou e 1/3 absteve-se. No que respeita à capacidade de gerir um grupo de trabalho, 48\% dos inquiridos não assumiu qualquer tipo de posição, porém 33\% discordaram e apenas 20\% se sentiria capaz de realizar tal função. $85 \%$ dos inquiridos referiram sentir necessidade de crescer cada vez mais na função que desempenham. 86\% concordaram que os prémios atribuídos aos colaboradores representam um factor de motivação. Quanto ao alcance do cargo mais elevado dentro da instituição 47\% afirmou não ser o seu objectivo no entanto $1 / 3$ dos inquiridos abstevese, tendo apenas 19\% considerado esse objectivo. De realçar que 95\% consideraram de extrema importância a motivação que Ihes é transmitida quando o seu trabalho é elogiado pelos seus superiores.

$81 \%$ dos inquiridos afirmaram ser uma pessoa com grande motivação.

\section{Motivação ligada ao envolvimento}

$81 \%$ dos participantes considerou-se ser uma pessoa com grande motivação. Apenas 15\% consideraram o seu trabalho monótono. Emocionalmente, referem sentir-se envolvidos com a instituição onde exercem as suas funções cerca de $86 \%$ e $91 \%$ consideraram os seus conhecimentos determinantes na forma de trabalhar.

Apenas 15\% referiu não se aborrecer quando não compreendem a finalidade das suas funções sendo que $81 \%$ partilha de opinião inversa (restante \% não concordou nem discordou).

Quanto à função desempenhada, 86\% dos profissionais da USF afirmaram identificar-se com as suas funções na medida em que vivenciam os seus valores dentro da função que desempenham e da corporação a que pertencem existindo ainda uma taxa de indecisão relativamente a esta questão de 14\%. No que respeita às formas de remuneração alternativa, apenas $15 \%$ discordaram que trabalhariam com maior empenho e satisfação se as mesmas existissem, 29\% manifestaram indecisão em relação a esta questão e os restantes concordaram.

\section{Discussão}

Os processos que envolvem as atividades diárias das organizações que buscam a eficácia requerem um comportamento participativo e motivado por parte dos trabalhadores.

Na generalidade:

- Quanto à dimensão da motivação tendo em vista a organização em que se trabalha, os participantes revelam-se maioritariamente satisfeitos com as condições e as funções desempenhadas; não sendo, porém, possível afirmar o mesmo respectivamente à remuneração e ao processo de tomada de decisões.

- Na motivação para o desempenho a maioria revela desenvolver estratégias para atingir os seus objectivos e considera que tarefas diversificadas são importantes para o bom desempenho das funções, quebrando assim a monotonia. 
- A motivação ligada à realização e poder revelou que apenas uma minoria se considera capaz de gerir um grupo de trabalho e anseia alcançar o cargo mais elevado dentro da instituição. É, porém, consensual que os prémios atribuídos e os elogios por parte dos superiores constituem factores motivacionais importantes.

- Na motivação ligada ao envolvimento, a maioria dos partipantes consideraram-se como pessoas de grande motivação e envolvidas com a instituição em que trabalham, pois identificam-se com as suas funções na medida em que vivenciam os seus valores dentro da função que desempenham e da corporação a que pertencem.

É fundamental ter uma perspectiva coerente de quais as directrizes que se devem assumir para os trabalhadores agirem num determinado sentido, uma vez que a motivação é um fenómeno altamente complexo, que

\section{Referências Bibliográficas}

1. Antunes V. (2011), "Perfil Motivacional dos Educadores de Infância do Concelho de Torres Novas"; Disponível em: http://recil.grupolusofona.pt/jspui/handle/10437/1526, a 17 de Abril de 2013.

2. Barbosa M. (2009), "A Motivação dos Candidatos à Força Aérea Portuguesa: Adaptação e Validação de um Instrumento"; Disponível em: https://repositorio.iscteiul.pt/ handle/10071/1868?mode=simple, a 19 de Abril de 2013.

3. Ferreira A., Diogo C., Ferreira M., Valente A. (2006), "Construção e validação de uma escala multifactorial de motivação no trabalho", Comportamento Organizacional e Gestão vol. 12, n. $^{\circ} 2,187-198$.

\section{Conflito de Interesses}

As autoras declaram não ter conflito de interesses em relação a este artigo.

Endereço para Correspondência:

Marina Carneiro

Telemóvel: 963545881

Email: marinaleac@gmail.com afecta uma multiplicidade de factores organizacionais e diferentes cuidados dever-se-ão ter em conta de forma a potencializar as competências e desempenho do indivíduo.

\section{Conclusões}

As influências no trabalho são multifatoriais, não se podendo minimizar os efeitos do fator humano a nível institucional e organizacional, sendo que a motivação representa uma variável determinante e que permite uma melhor caracterização profissional.

\section{Agradecimentos}

As autoras agradecem a todos os profissionais da USF do Mar que mostraram toda a disponibilidade em participar neste estudo.

4. Hackman J.R., Oldham G.R. (1980). Work Redesign. New York: Addison-Wesley Publishing Company.

5. McClelland D.C. (1989). Motivational factors in health and disease. American Psychologist, 44, 675-683.

6. Locke E.A., Latham G.P. (1990). A theory of goal setting and task performance. Englewood Cliffs, NJ: Prentice-Hall.

7. Allen N.J., Meyer J.P. (1990). Affective, continuance, and normative commitments to the organization: An examination of construct validity. Journal of Vocational Behaviour, 49, 252-276. 